\title{
"El pueblo crucificado" y \\ "la civilización de la pobreza". \\ "El hacerse cargo de la realidad" \\ de Ignacio Ellacuría*
}

\section{Jon Sobrino, \\ Centro de Reflexión Teológica, \\ San Salvador.}

Quiero empezar estas palabras con unas breves aclaraciones. No soy un estudioso de Zubiri. Lo que conozco de él, lo aprendí sobre todo a través de Ellacuría, y no tanto por la lectura de sus escritos sobre Zubiri, sino por el sabor zubiriano, digámoslo así, que rezumaba su modo de pensar. Fijándonos ya en Ellacuría, de su pensamiento conocí más lo que tiene de teológico que de filosófico. Noté en él el influjo de Rahner, su profesor de teología, en Innsbruck; el de Marx, en buena medida, y en gran medida - lo que suele ser menos tenido en cuenta-, el de la tradición bíblico-jesuánica, la de san Ignacio de Loyola y la de Monseñor Romero. Finalmente, creo que la realidad salvadoreña social, y en su tiempo incluso eclesial, ejerció un impacto e influjo decisivos sobre su pensamiento.

En esta ponencia quiero analizar dos contenidos de su visión de la realidad: "el pueblo crucificado" y "la civilización de la pobreza". Ambos son temas de madurez, no reflexiones juveniles y pasajeras, que Ellacuría consideró muy importantes. Hoy, sin embargo, suelen ser ignorados, a no ser en algunos escritos sobre su teología ${ }^{1}$. No sé si esto ocurre dentro de la discusión filosófica, pero sí ocurre cuando se habla globalmente de Ellacuría. Es el "Ellacuría olvidado",

- Ponencia presentada en la clausura del II Congreso Internacional de Filosofía Xavier Zubiri, celebrado en la Universidad Centroamerciana "Jose Simeón Cañas" del 21 al 24 de junio de 2005.

1. Mencionemos dos tesis escritas sobre el tema. M. Maier, Theologie des Gekreuzigten Volkes. Der Entwurf einer Theologie der Befreiung von Ignacio Ellacuría und Jon Sobrino, Universidad, Insbruck, 1992; K. Burke, The ground beneath the cross. 
olvido comprensible, pero también empobrecedor e irresponsable, pues este Ellacuría contracultural puede seguir siendo un aguijón socrático, incómodo, pero también positivo - y necesario - , en el mundo actual.

Se podrá decir que las cosas han cambiado y que el mismo Ellacuría pondría en guardia contra la repetición mimética de conceptos, y ciertamente, instarla a historizarlos. Con todo, me parece necesario volver sobre estos temas, para superar el actual encubrimiento de la realidad, que, en muy buena medida, sigue siendo la de pueblos crucificados, y para apuntar a una civilización más humana, que todavía puede ser descrita como civilización de la pobreza.

\section{1. "Hacerse cargo de la realidad"}

Ellacuría comprendía la estructura formal de la inteligencia como "aprehender la realidad y enfrentarse con ella"2, lo cual se desdobla en tres dimensiones: "hacerse cargo de la realidad" (dimensión intelectiva), de origen zubiriano, a lo cual añadió el "cargar con la realidad" (dimensión ética) y el "encargarse de la realidad" (dimensión práxica). Por mi parte, he añadido - más por experiencia e intuición que por reflexión teórica - una cuarta dimensión: "dejarse cargar por la realidad" (dimensión de gracia), sobre lo cual volveremos.

Cuando llegué a conocer el pensarniento de Ellacuría, lo que más me impactó fue su énfasis en el encargarse de la realidad, hasta el punto de que -eran los inicios de la teología de la liberación - llegó a definir la teología como el momento ideológico de una praxis ${ }^{3}$, cuya finalidad era "la mayor realización posible del reino de Dios en la historia"4. Por mi parte, traté de retomar la intuición y definí la teología como intellectus amoris (iustitiae, misericordiae)", más allá del intellectus fidei, proveniente de Agustín, y del intellectus spei, como lo reformulaba Jürgen Moltmann, en 1978, en su Teología de la esperanza.

Todavía más me impactó "el cargar con la realidad". Viniendo de otros lares, suponía una novedad tocal escuchar - y percibirlo en la persona de Ellacuria - que la inteligencia "no se ha dado al hombre para evadirse de sus compromisos reales, sino para cargar sobre sí con lo que son realmente las cosas y con lo que

Historical Reality and salvation in the theology of Ignacio Ellacuria, Weston Jesuit School of Theology, 1997.

2. "Hacia una fundamentación filosófica del método teológico latinoamericano", ECA $322-323$ (1975) 419.

3. "La teologla como momento ideológico de la praxis eclesial", Esıudios eclesiasticos 207 (1978) 457.

4. "Aporte de la teología de la liberación a las religiones abrahámicas en la superación del individualismo y del positivismo", Revista Latinoamericana de Teologfa 10 (1987) 9.

5. "Teología en un mundo sufriente. La teología de la liberación como intellectus amoris", Revisfa Latinoamericana de Teologfa 15 (1988) 243-266. 
realmente exigen" ${ }^{\circ}$. Esto quiere decir que no se puede inteligir adecuadamente la realidad sin cargar con lo oneroso de ella - lo cual, pienso, no es muy tomado en cuenta hasta el día de hoy. Su asesinato bien puede fungir como símbolo de ese cargar con la realidad. Ellacuría la pensó y cargó con ella hasta el final. Y no es casual que la teología salvadoreña fuera pionera en hacer de la persecución y del martirio temas centrales, también en cuanto teóricos.

Comprender las dimensiones práxica y ética de la inteligencia fue lo más novedoso. Pero, dentro de la perichoresis entre las diversas dimensiones de la inteligencia, también empecé a percibir la hondura implicada en el "hacerse cargo de la realidad", cosa que no es tan simple como parece. El mismo Ellacuría nos lo advierte. El hacerse cargo de la realidad supone "un estar en la realidad de las cosas -y no meramente un estar ante la idea de las cosas o en el sentido de ellas -, un estar "real" en la realidad de las cosas, que en su carácter activo de estar siendo es todo lo contrario de un estar cósico e inerte e implica un estar entre ellas, a través de sus mediaciones materiales activas"?.

\section{2. "El pueblo crucificado"}

Cuando Ellacuría "se hizo cargo de la realidad" del tercer mundo, la aprehendió muy importantemente como "pueblo crucificado". En 1977, escribió un texto que, entre nosotros, fue muy conocido: El pueblo crucificado. Ensayo de soteriología historica ${ }^{8}$. Y en 1981, en uno de sus exilios en Madrid, volvió a insistir sobre el tema, en otro más breve. Escribió unas palabras que, a pesar de los cambios de estos años, siguen siendo lúcidas y, en buena medida, insustituibles:

Entre tantos signos como siempre se dan, unos llamativos y otros apenas perceptibles, hay en cada tiempo uno que es el principal, a cuya luz deben discernirse e interpretarse todos los demás. Ese signo es siempre el pueblo históricamente crucificado, que junta a su permanencia la siempre distinta forma histórica de su crucifixión. Ese pueblo es la continuación histórica del siervo de Jahvé, al que el pecado del mundo sigue quitándole toda figura humana, al que los poderes de ese mundo siguen despojando de todo, le siguen arrebatando todo hasta la vida, sobre todo la vida?.

6. "Hacia una fundamentación", p. 419.

7. Ibid. Estas últimas palabras sugieren - formulado en otro lenguaje - que la realidad no se "asoma" en las cosas sin más. Decía Rahner que "la realidad quiere tomar la palabra", pero hay que dejarla hablar, y una vez que ha hablado, hay que respetar su palabra. Y que eso no es evidente, nos lo advierte Pablo, quien ve en el ser humano la posibilidad - y el hecho- de "oprimir la verdad de la realidad" (Rom 1, 18).

8. Publicado por $C R T$, México. 1978, y reproducido después de su asesinato, en Revista Latinoamericana de Teologra 18 (1989) 305-333.

9. "Discemir el 'signo' de los tiempos", Diakonía 17 (1981) 58. 
Desde un punto de vista teórico-teológico, lo más específico del primer texto consiste en relacionar pueblo crucificado y salvación histórica, y lo más específico del segundo consiste en presentarlo como realidad, donde se expresa la historia con máxima densidad, de la cual hay que encargarse y con la cual hay que cargar.

\subsection{El pueblo crucificado como negatividad: "signo de los tiempos"}

Ellacuría no eligió ese lenguaje al azar, ni sólo por su resonancia cristiana, pues aplicar al "pueblo" lo que se dice de "Cristo" no era evidente, en su tiempo. Lo eligió, porque quería recalcar, programáticamente, la negatividad de la realidad; así le afectaba y así la veía. Y eso fue central en todo su pensamiento. Ya al proponer el carácter desideologizante y desencubridor de la realidad encubierta que debe tener la filosofía, reclamaba a Heidegger que "quizás en vez de preguntarse por qué hay más bien ente que nada, debería haberse preguntado por que hay nada - no ser, no realidad, no verdad, etc. - en vez de ente"lo.

$Y$ "el pueblo crucificado" no expresa una negatividad cualquiera, sino específica. Economistas y sociólogos hablaban de mundo de pobreza y miseria, de dependencia, injusticia y opresión. Pero pocos -quizás con la excepción de Monseñor Romero- formularon la realidad con la extremada hondura que expresa el concepto de "pueblo crucificado". Veámoslo.

Con esas palabras, Ellacuría quiere nombrar a inmensas mayorías. De ahí el lenguaje de "pueblo", "pueblos", etc, que están transidas de muerte, y no de una muerte natural, sino de una muerte histórica, que toma la forma de crucifixión, asesinato, activa privación histórica de la vida, lenta o rápidamente. A esa muerte, producto de la injusticia, acompaña la crueldad, el desprecio y, por otra parte, el encubrimiento. A esto suelo añadir que al pueblo crucificado, además, se le niega palabra y hasta nombre, y con ello, se le niega existencia. El pueblo crucificado no "es", y el mundo de abundancia impide o dificulta que "llegue a ser". Así, puede desentenderse - sin mala conciencia - de lo que ocurre a esas mayorías".

Este pueblo crucificado, en su negatividad, es "signo". Usando conceptos de la Gaudium et Spes 4, 1965, afirma Ellacuría que el pueblo crucificado caracteriza centralmente nuestro tiempo, no es sólo algo factual, que puede ser tenido en cuenta, sino algo central, que debe ser tenido en cuenta, sin lo cual no se hace uno cargo a cabalidad de la realidad. Pero Ellacuría dio un paso que no dio

10. "Función liberadora de la filosofía", ECA 435-436 (1985) 50.

11. Permitaseme un ejemplo, aunque pueda parecer simplón. Los ciudadanos de Estados Unidos "existen", "son", y eso se muestra, entre otras cosas, en que "tienen calendario": el 11-S -y el 11-M, en España - existen, son cosa real. Sin embargo, el 7-O (de 2001) y el 30-M (de 2003), cuando occidente bombardé Afganistán e Iraq, no existen. El tercer mundo "no tiene calendario", "no existe". 
el concilio: tuvo la audacia de concretar el signo más importante, alrededor del cual giran y se explican los demás. Eso - proclamar el signo de los tiemposes lo que, de otra manera, ya habra hecho Medellín, en 1968, y que prenunciaba el texto citado de Ellacuría. Los obispos comienzan con estas palabras ${ }^{12}$ :

Existen muchos estudios sobre la situación del hombre latinoamericano. En todos ellos se describe la miseria que margina a grandes grupos humanos. Esa miseria como hecho colectivo es una injusticia que clama al cielo (Justicia 1).

\subsection{El pueblo crucificado como posilividad: "trae salvación"}

Ellacuría conocía bien la tradición bíblico-jesuánica, en la cual la negatividad puede ser vehículo de positividad. Ciertamente, así es en Cristo crucificado, confesado como hijo de Dios y salvador, pero, en Marcos sobre todo, lo es en y a través de la cruz (Mc 15, 38). Más cercano a nuestro tema, Isaías presenta en los cantos del siervo de Jahvé (Is 52, 13-53, 12), una misteriosa figura - real o imaginaria, individuo o colectividad -, destrozada por los pecados del mundo y que trae salvación.

Este siervo es, en primer lugar, varón de dolores, acostumbrado al sufrimiento, llevado a la muerte - por lo que hacen otros - sin defensa y sin justicia, desestimado, despreciado por todos. En segundo lugar, no sólo no se lo considera como posible salvador, sino todo lo contrario; se lo considera como leproso, condenado, herido de Dios y humillado, y aparece además como pecador: le dieron sepultura con los malhechores y fue contado entre los pecadores.

Pero más novedoso y audaz es todavía el significado que Isaías atribuye a esa figura del siervo, en lo cual Ellacuría encuentra los elementos fundamentales para una "soteriología histórica" también para hoy: su sufrimiento y su muerte inocente traen salvación. Del siervo se dice que su estado no se debe a sus pecados, sino que sufre, sin haber cometido pecado: fue traspasado por nuestras rebeliones, triturado por nuestros crímenes, herido por los pecados del pueblo... Se dice, entonces, que justificará a muchos. En nuestro lenguaje, se dice que salvará a todos, también a sus victimarios, y la razón es que cargó con los crímenes de ellos. Comenta Ellacuría: “ ¡Sólo en un difícil acto de fe, el cantor del siervo es capaz de describir lo que aparece como todo lo contrario a los ojos de la historia!"13.

12. A este signo añadieron otro, igualmente fundamental: "un anhelo de emancipación total de toda servidumbre, de maduración personal y de integración colectiva" (Introduccion 4).

13. ."El pueblo crucificado", p. 326. 
Teniendo presente a ese siervo $-y$ dentro del círculo hermenéutico-, Ellacura "se hizo cargo" de la realidad de los pueblos del tercer mundo, y analizó también su dimensión salvífica. En las capacidades positivas del pueblo vio esperanza de liberación, y así, por ejemplo, con Monseñor Romero, defendió y animó a la organización popular. Pero la vio también en su negatividad, en cuanto pueblo sufriente, "crucificado", en lo que ahora nos concentramos. Y para que esa palabra no fuera vana, hizo un esfuerzo teórico para historizar en qué consistía esa salvación, proveniente de los crucificados. Más adelante, hablaremos, en mayor detalle, de la salvación que viene de abajo. Baste recordar ahora dos elementos importantes de esa salvacion, sorprendentes y no tomados en cuenta.

El pueblo crucificado ofrece "luz" (en Is 42,$6 ; 49,6$ se dice del siervo que es "luz de las naciones", aunque en este canto no se trata todavía del siervo sufriente). En nuestros días, dice Ellacuría, el tercer mundo ofrece luz al primer mundo para que éste se vea en su verdad, lo cual es elemento importante de salvación. Para mostrarlo, usó dos metáforas gráficas: el pueblo crucificado es como un espejo invertido en el cual, al verse desfigurado, el primer mundo se ve en su verdad, que intenta ocultar o disimular. $Y$ es también lo que aparece en el coproanálisis, el examen de heces del primer mundo. La existencia de pueblos crucificados muestra la verdad de su estado de salud.

Un segundo elemento de salvación es la "esperanza". En 1989, Ellacuría habló dos veces de ello. Desde su sufimiento, el tercer mundo mantenía esperanza, que ofrece a un primer mundo sin ella. Cito por entero el primer texto de diafana utopía y profecía:

Toda esta sangre martirial derramada en El Salvador y en toda América Latina, lejos de mover al desánimo y a la desesperanza, infunde nuevo espíritu de lucha y nueva esperanza en nuestro pueblo. En este sentido, si no somos un "nuevo mundo" ni un "nuevo continente", sí somos, claramente, y de una manera verificable $-y$ no precisamente por la gente de fuera - un continente de esperanza, lo cual es un síntoma sumamente interesante de una futura novedad frente a otros continentes que no tienen esperanza y que lo único que realmente tienen es miedo ${ }^{14}$.

El segundo texto es de su último discurso, el 6 de noviembre de 1989. "Lo que queda por hacer es mucho. S6lo utópica y esperanzadamente uno puede creer y tener ánimos para intentar con todos los pobres y oprimidos del mundo revertir la historia, subvertirla y lanzarla en otra dirección"1s.

"Verdad" y "esperanza" son - si se les quiere tomar en cuenta- importantes aportes salvíficos del pueblo crucificado. Pero además, aporta impulsos para

14. “Quinto Centenario de América Latina ¿descubrimiento o encubrimiento?”, Revista Latinoamericana de Teología 21 (1990) $281 \mathrm{~s}$.

15. "El desafío de las mayorías pobres", ECA 493-494 (1989) 1078. 
poner a la salvación en la dirección correcta y para trabajar por ella; cuestiona cuán adecuada es o no la comprensión de la salvación, social, ambiental, religiosa en el mundo que no es el de los pobres, y menos en el mundo que los produce; y ayuda a desenmascarar el dogma de que un pueblo de pobres sólo puede recibir y no dar - lo cual es de vital importancia para que las sociedades de abundancia no caigan en arrogancia y, así, en deshumanización.

Ellacuría es consciente de que aceptar que la salvación venga - también - de abajo no es algo que se reconoce usualmente, ni en filosofías, ni en ideologías, ni en teologías, aunque recuerda la idea de Marx de que en los oprimidos hay posibilidad de emancipación, "en la formación de una clase de la sociedad civil que no es una clase de la sociedad civil; de una clase que es la disolución de todas; de una esfera que posee un carácter universal debido a sus sufrimientos universales y que no reclama para sí ningún derecho especial, porque no se comete contra ella ningún daño especial, sino el daño puro y simple"16. Hay aquí un intento de pensar el papel de los débiles (una clase social, el proletariado, aunque se excluye a los más desheredados) en la salvación histórica. El canto del siervo es más radical. Por ello lo utiliza Ellacuría para formular su comprensión de la realidad.

\subsection{El "siempre" del pueblo crucificado}

Todo lo dicho causa estupor. Pero el "siempre" puede causar un estupor mayor: "ese signo es siempre el pueblo históricamente crucificado, que junta a su pernnanencia la siempre distinta forma histórica de su crucifixión". ¿Se puede decir esto responsablemente? Hoy se puede vislumbrar una disminución importante de la pobreza y se puede soñar incluso con su desaparición, en China y la India, por ejemplo. Aunque no hay que olvidar que hasta ahora, los reveses en la lucha contra la pobreza son también notables y que la pobreza relacional (el ricachón y el pobre Lázaro), el inmenso agravio comparativo entre ricos y pobres, no disminuye, sino que aumenta escandalosamente. En cualquier caso, razón lleva Leonardo Boff: "Cuando juzguen nuestro tiempo las generaciones futuras, nos tacharán de bárbaros, inhumanos y despiadados por nuestra enorme insensibilidad frente a los padecimientos de nuestros propios hermanos y hermanas"17.

Personalmente pienso que, aun desde un punto de vista analítico, él "siempre" de Ellacuría es verosímilis, sobre todo si se analiza la crucifixión de los pueblos no sólo como insatisfacción de sus necesidades básicas, sino también

16. Citado en I. Ellacuria, "El pueblo crucificado", p. 308.

17. La oración de San Francisco, Santander, 1999, p. 98.

18. Al escribir estas líneas leo los siguientes titulares en la página Web de la $B B C$ : "Cada cinco segundos muere un nin̄o de hambre en el mundo", "842 millones tienen hambre", "No se cumplirán "las metas del milenio"”, "Aumenta la distancia entre pobres y ricos". 
como la ignorancia e indignidad a que se los condena, la depredación de sus culturas y el aberrante agravio comparativo que se les hace con respecto a los pueblos de abundancia. Cambian las cosas y cambian los paradigmas. Pero puede uno preguntarse si no existe algo transparadigmático, y si no hay principios de maldad y pecaminosidad que atraviesan la historia, que tienen un dinamismo de crucifixión, que cambia de formas, pero sigue produciendo muerte. A eso apunta el "siempre". Y parece que sI los hay.

\subsection{La importancia para el presente}

Se podrá decir que, a fin de cuentas, "el pueblo crucificado" es sólo lenguaje, pero hay que recordar que estamos inmersos en una "batalla del lenguaje", a la cual se dedican ingentes recursos. No es lo mismo hablar de "subdesarrollo" y menos de "pueblos en vías de desarrollo", que de "crucifixión". Lo primero se puede cooptar fácilmente. Lo segundo no, y por eso se silencia. Quizás el lenguaje de "pueblos crucificados" ayude a ganar la batalla del lenguaje, y, así, la batalla alrededor de la verdad.

Más de fondo, el mundo de abundancia, aun con los añadidos de democrático, pluralista, global, necesita una sacudida, comparable a la que exigía Kant: "despertar del sueño dogmático". En buena medida, occidente sigue sumido en "el sueño de cruel inhumanidad", ignorando, silenciando, maquillando terribles realidades, de las cuales es en muy buena parte responsable. Usar el lenguaje de "pueblo crucificado" puede ayudar a sacudir para despertar y actuar. Esto es lo que hizo un fraile dominico, Antonio Montesinos, en 1511, en La Española. En el tercer domingo de adviento echó en cara a los encomenderos los horrores que estaban haciendo, y terminó: “¿Cómo estáis en sueño tan letárgico dormidos?".

También tiene importancia desde un punto de vista teológico. En GS 11 se vuelven a mencionar los "signos", pero no ya como lo que caracteriza a una época, sino como "los signos verdaderos de la presencia o de los planes de Dios"; son "signos" en su acepción historico-teologal. Para la fe, esto implica que el pueblo crucificado es lugar de Dios, en la línea de Pablo y Marcos, Bonhoeffer, Moltmann y otros que hablan de un "Dios crucificado". En cualquier caso, se acepte o no este theologoumenon, en la negatividad del pueblo crucificado se hace presente la realidad con últimidad radical, lo cual, al menos, la defiende de su trivialización.

Por último, el "hacerse cargo" de la realidad, en cuanto "pueblo crucificado" y no de otra forma, apunta a formas, suficientemente concretas, que deben adoptar las otras dimensiones de la inteligencia. Así, el "encargarse de la realidad" lo formul6 Ellacuría programáticamente como la praxis de "bajar de la cruz al pueblo crucificado" - y permítaseme recordar la raíz de esta idea. Ignacio de Loyola pide al pecador arrepentido que, ante Cristo crucificado, se pregunte "qué he hecho, qué hago y qué voy a hacer por Cristo". Esto significa adoptar una actitud no sólo de agradecer el perdón obtenido, sino de un hacer, y preguntarse después qué 
hacer. La respuesta a esta pregunta es lo que, ante el pueblo crucificado, historizo Ellacuría" como "bajarlo de la cruz". Por lo que toca al "cargar con la realidad", consiste en la disposición a correr riesgos, la firmeza y fidelidad hasta el final, y la disponibilidad a terminar en la misma cruz del pueblo crucificado.

El "dejarse cargar por la realidad", cuando ésta es la del pueblo crucificado, apunta a una paradoja, central en la fe cristiana, aunque puede ir más allá de ella. En lenguaje teológico, significa que en el pueblo crucificado hay "gracia", es decir, que el pueblo crucificado carga con nosotros ${ }^{20}$, y lo hace de diversas formas: nos da nuevos ojos para ver, nos da manos nuevas para trabajar, nos da espaldas amplias para soportar. Y nos da esperanza. La razón última para hacer esta afirmación es indefensa: así ocurre. Que Monseñor Romero tenía que cargar con su pueblo es evidente, pero decía también que "con este pueblo no cuesta ser buen pastor, mueve a su servicio". Así lo vio Ellacuría, y lo expresó reformulando el texto de Monseñor. "Completando lo que él [Monseñor Romero] solía decir "con este pueblo qué fácil es ser buen pastor', puede decirse 'con este pastor qué fácil es ser pueblo de Dios"'21. La realidad del pueblo cargaba con Monseñor y la realidad de Monseñor cargaba con el pueblo.

Para terminar este punto, podemos preguntamos de dónde le vino a Ellacuría la luz para "hacerse cargo de la realidad" de esa manera y formularla como "pueblo crucificado". No tengo una respuesta apodíctica, y esa aprehensión tendrá varias raíces. En mi opinión, Ellacurfa se dej6 afectar por la realidad, desde una honradez primordial ante ella, dejándola ser lo que es - la versión secular barthiana del

19. "Lectura latinoamericana de los Ejercicios Espirituales de san Ignacio" Revista Latinoaericana de Teología 23 (199I) 119-124. Más específicamente, en "Las iglesias latinoamericanas interpelan a la Iglesia de España", Sal Terrae 3 (1982) 230. Por lo que toca a las formas históricas de esa praxis, Ellacurfa impulso diversos quehaceres: saberes para desarrollar modelos que posibiliten la vida de las mayorfas, la promoción de la organización popular, la negociación que pusiera fin a la guerra; y trabajo por poner en esa línea a la Iglesia y a la Compañía. A todo esto sólo quiero añadir lo que ya he insinuado. Al poner nombre a las victimas, con lo cual se las saca del anonimato, se les concede existencia - piénsese en la inexistencia a la que se ha condenado al Africa subsahariana, Afganistán. Y se les otorga "dignidad", al proclamar, en lenguaje cristiano, que son hoy el "Cristo crucificado", el "siervo doliente de Yahve".

20. Enrique Gómez Garcla, un estudioso de Zubiri, encuentra en él una cierta fundamentación filosofica para la idea de la graciosidad de la realidad. Dice asi: "la 'graciosidad' que encierra la realidad, y que sólo el hombre con esplritu es capaz de percibir como la presencia providente de Dios en su creación, encuentra su desarrollo más explf́cito en la comprensión zubiriana del poder de lo real, que propicia la dimensión de fundamentalidad", en "De la 'espiritualidad de lo real' a la 'filosofia de la realidad'. Aportes de X. Zubiri a la espiritualidad de la liberación", Revista de Espiritualidad 63 (2004) 548s.

21. "La UCA ante el doctorado concedido a Monseñor Romero", ECA (1985) 168. 
teologal "dejar a Dios ser Dios" - y desde el enraizamiento real - no sólo conceptual-, en una tradición bíblico-jesúanica, de cuya savia bebió en el misterio de la libre decisión. Esto operó un "milagro" que no es frecuente. En definitiva, la realidad se le apareció como pueblo crucificado. Es el opthe con que se narran las apariciones del resucitado. Hubo don y gracia. Ellacuría respondió y correspondió.

\section{La civilización de la pobreza ${ }^{22}$}

\subsection{Desenmascaramiento de la "civilización de la riqueza"}

En sus últimos años, Ellacuría estaba convencido de que es necesario "otro" mundo - formulado en lenguaje de hoy - para no caer en inhumanidad, pero no cualquier mundo "otro". Era necesario "revertir la historia, subvertirla y lanzarla en otra dirección"23. A eso llamó la civilización de la pobreza, sobre lo que escribió tres textos ${ }^{24}$, para superar la actual civilización de la riqueza. En ello insistió hasta el final, y si asusta el lenguaje, bien se podría hablar de una civilización de la "pobreza solidaria" o de la "austeridad compartida", aunque Ellacuría insistió en el lenguaje de "pobreza".

La civilización de la riqueza, dice Ellacuría, ofrece desarrollo y felicidad, y los medios para conseguir ambas cosas. Por lo que toca a lo primero, "en última instancia, propone la acumulación privada del mayor capital posible por parte de individuos, grupos, multinacionales, estados o grupos de estados, como la base fundamental del desarrollo"2s. Y por lo que toca a lo segundo, propone "la acumulación poseedora, individual o familiar, de la mayor riqueza posible como base fundamental de la propia seguridad y de la posibilidad de un consumismo siempre creciente como base de la propia felicidad"26.

Su juicio sobre esa civilización es muy crítico, aunque no simplista. "No se niega que tal tipo de civilización, vigente tanto en el este como en el oeste y que debe llamarse civilización capitalista - sea capitalismo de Estado o capitalismo privado- ha traído bienes a la humanidad, que como tales bienes deben ser conservados y propiciados (desarrollo científico y técnico, nuevos modos de

22. Algunas reflexiones de este apartado han aparecido en "Epllogo. Revertir la historia", Concilium 308 (2004) 145-154.

23. "El desafío", p. 1078.

24. "El reino de Dios y el paro en el Tercer Mundo", Concilium 180 (1982) 588 - 596; "Misión actual de la Compañía de Jesús", escrito en 1983 y publicado póstumamente, en Revista Latinoamericana de Teología 29 (1993) 115-126; "Utopía y proletismo", Revista Latinoamericana de Teología 17 (1989), publicado tambiên en I. Ellacuría, J. Sobrino, Mysterium Liberationis, Conceptos fundamentales de la reología de la liberación I, Madrid, 1990, San Salvador, 1991, pp. 393-442.

25. "Utopia", p. 170.

26. lbid. 
conciencia colectiva, etc.), pero ha traído males mayores y sus procesos de autocorrección no se muestran suficientes como para revertir su curso destructor"27. Los "males mayores" de esa civilización son que no satisface las necesidades básicas de todos, $\mathrm{y}$, en lo que insistió cada vez con más fuerza, que no genera esplritu, valores que humanicen a personas y sociedades.

Por lo que toca a la vida de las mayorias, afuma Ellacuría que no hay recursos para que la solución que ofrece la civilización de la riqueza -que desde la pespectiva económica la llama "civilización del capital"- sea universal, y por ello tampoco lo es éticamente, siguiendo a Kant. No sé qué diría Ellacuría en la actualidad, en tiempos de globalización económica, y cuando se vislumbran algunas posibilidades para disminuir la pobreza y hacer universal el sustento diario. Pero lo que seguiría sin ser universalizable es el nivel de vida de estadounidenses, europeos o japoneses. Consumen tal cantidad de recursos, materias primas y energía que no puede alcanzar para la población mundial ${ }^{2 \mathrm{~g}}$.

Por lo que toca a lo segundo, esta civilización, en lo fundamental, está basada en y ofrece un espíritu que, en definitiva, lleva a la deshumanización. Es la civilización del individuo, del éxito, del egoísta buen vivir. Y el aire que respira el espíritu se enrarece todavía más cuando el occidente que la produce se comprende a sí mismo no sólo como logro de talento y nobles esfuerzos - en parte, muy reales, a los cuales se añaden también una secular y gigantesca depredación histórica-, sino como fruto de una predestinación, como antaño se comprendían los pueblos elegidos según las religiones.

Fijándonos en Estados Unidos, es un país que actúa con la naturalidad y la prepotencia de quien obedece a un "destino manifiesto". Queda justificado como imperio, se siente enviado al mundo como misionero de la divinidad-riqueza y piensa que se lo deben agradecer como a generoso benefactor. Se podrá decir que hay también reacciones en contra de ese sentido de la vida, pero son desproporcionadamente pequeñas en cantidad. Y en calidad no sé qué grado de disponibilidad existe a dejar de disfrutar de los bienes de la civilización de la riqueza. Esto es verdad, en diversos grados, de todo el primer mundo. Ese espíritu de prepotencia deshumaniza. Por su naturaleza tiende a generar desprecio en unos y servilismo o respuestas irracionalmente violentas en otros.

Desde esa convicción dijo Ellacuría que Estados Unidos "tiene una mala solución"29 - lo cual es peor que no tener solución, como es el caso en el tercer

27. Ibid., p. 173

28. Un dato. No sé si y cuánto han cambiado las cosas, pero todavía hace sólo diez años, la economía de Estados Unidos consumía casi la tercera parte de la producción anual global de materias primas minerales para atender el nivel de consumo habitual del 6 por ciento de la población mundial. Cfr. I. Zubero, Las nuevas condiciones de la solidaridad, Bilbao, 1994, p. 92.

29. "Quinto Centenario", p. 277. 
mundo. Y generalizando, dijo que los países de abundancia "no tienen esperanza" - la cual sí existe en el tercer mundo-, sino que "lo único que realmente tienen es miedo"30. Personalmente pienso que, sea cuales fueren las mejoras en paliar la pobreza, no se ve cómo puede tener sentido un mundo en que la igualdad, y nada digamos la fraternidad, no son los ideales que guían el desarrollo. Y no puede tenerlo si escenifica recurrentemente la parábola del ricachón y del pobre Lázaro - sin que el abismo vaya disminuyendo, sino aumentando, como anualmente lo constata el PNUD. La conclusión de Ellacuría es lapidaria: esa civilización sufre un "fracaso humanista y moral" 31 .

\subsection{Las sospechas}

Ellacuría no sólo desenmascaró los "graves males" de la civilización de la riqueza, contra los que ésta no produce autoconrectivos suficientes, sino que también desenmascaró lo que en occidente es tenido, en la práctica, sin discusión, como "bienes". Eso lo hizo pensar, y lo hizo sospechar, que occidente presentaba esos bienes ideologizadamente para hacerlos intocables $\mathrm{y}$, en la práctica, no criticables. Veamos dos ejemplos: la sospecha de la democracia e incluso de los derechos humanos. Los textos son de 1989.

Para Ellacuría, la democracia es algo importante, obviamente, sobre todo viviendo en regímenes de seguridad nacional. Pero en conversaciones espontáneas solía decir, por ejemplo, que "Estados Unidos valora la democracia y actúa democráticamente dentro de sus fronteras, pero fuera de ellas, la democracia le tiene absolutamente sin cuidado". Estas son palabras mayores, pues Estados Unidos no es un flatus vocis, sino una muy sólida realidad que, supuestamente, ha encarnado la esencia de la democracia. Por el mero hecho de sancionar con su modo de proceder la desigualdad absolutamente antidemocrática, expresada en la desigualdad del "dentro" y "fuera" de Estados Unidos, no sólo cae en hipocresía, sino en contradicción conceptual. Y pensando en lo que necesitaba El Salvador, solía decir que "en lugar de democracia [la oferta propagandística] lo que necesitamos son derechos humanos". Es decir, la oferta - honrada o hipócrita- de superestructuras políticas democráticas, no garantiza lo fundamental: una vida justa.

Pero también formuló la sospecha teóricamente: "lo que busca el manejo ideologizado del modelo democrático no es la autodeterminación popular respecto del modelo político y económico, sino el encubrimiento de la imposición capitalista" ${ }^{2}$. La democracia tiene graves limitaciones, expresa la versión política de la civilización de la riqueza, y es manipulable, lo cual no debiera extrañar,

30. $l$ bld. p. 282.

31. "Utopia", p. 173.

32. lbid., p. 152. 
por ser cosa creada, que dicen los téblogos. Pero si esa manipulación es masiva, si lleva a inmensas crueldades, si necesita de la mentira institucional, en los medios y en foros internacionales, si es practicada por la máxima y mejor expresión de la democracia, Estados Unidos, y, sobre todo, si es recurrente, entonces, la manipulación que se hace de la democracia no puede ser considerada como un mero accidente, sino que parece pertenecer a su esencia histórica, tal como se practica en occidente, y más específicamente, en sus relaciones con las mayorías pobres del planeta. Que haya llevado también cosas buenas a las antiguas colonias, que sea el "menor de los males", es una cosa, pero que no se tenga en cuenta su grave potencial histórico de deshumanización es otra. Ellacuría en su análisis no partía del concepto de democracia, sino de verla funcionar in actu, desde y para el tercer mundo, no desde y para la parcela que son los países de abundancia. Por eso sospechaba.

Permítaseme intercalar en este contexto una reflexión teológica de Ellacuría. El Vaticano II, al hablar de la igualdad fundamental de todos los miembros del pueblo de Dios, además de tener en cuenta la tradición de la primera Iglesia, de hecho, también se inspiraba y estaba asumiendo en su doctrina valores centrales de la democracia. Desde Medellín, sin embargo, se elaboró un concepto teórico de Iglesia distinto, el de la Iglesia de los pobres. Va más allá de la "democracia" del concilio y recalca la desigualdad dentro de la Iglesia, no en favor de la jerarquía, sino de los pobres. Ellacuría profundiza este nuevo concepto y afirma que los pobres deben estar en el centro de la Iglesia como principio de su estructuración, organización y mision ${ }^{33}$. Esto no se opone al pueblo de Dios, ni a la democracia que éste implica, pero, indirectamente, saca a luz una debilidad teórica con grandes consecuencias prácticas: en un mundo que es mayoritariamente de pobres, no basta con igualdad (iojalá!) para que los pobres sean tomados en cuenta con seriedad, sino que hay que ponerlos en el centro para que no sean "expulsados" de la ciudadanía social y eclesial. Ellacuría insistía en ello por una razón evangélica: ellos pueden configurar a la Iglesia evangélicamente. Y desde el punto de vista social, de ello se desprende que una sociedad que pretenda ser en realidad "democrática", igualitaria, debe ser pensada y organizada desde los derechos de los que están en posición de desventaja.

Para Ellacuría, los derechos humanos son algo bueno, y, obviamente, que se practicasen era necesario y urgente en el país, y por ello trabajo. Sin embargo, al teorizarlos, también mostró sospechas importantes: los derechos humanos son presentados, por su esencia, como universales, pero en la realidad, no hay tal. Y esto es así, no sólo porque todavía no han llegado a ser reales para todos, sino porque muchas veces, en el mundo actual, el que sean reales para unos, supone

33. I. Ellacurfa, "La Iglesia de los pobres, sacramento histórico de liberación", ECA (1977) 717. 
su negación, y aun violación, para otros. "El problema de los derechos humanos es un problema no sólo complejo, sino ambiguo, pues en él no sólo confluye la dimensión universal del hombre con la situación real en la cual desarrollan su vida los hombres, sino que propende a ser utilizados ideológicamente al servicio no del hombre y de sus derechos, sino de los intereses de unos u otros grupos" ${ }^{\text {"34. }}$ No se podrá hablar de validez universal no ideologizada si no se tiene en cuenta el "desde" dónde y el "para" quién y "para" qué se proclaman... "Cuando el derecho se convierte en privilegio, niega su esencia universal y deja de ser derecho del hombre para ser privilegio de clase o de grupo de individuos" 35 .

Dos cosas son importantes en la desideologización de los derechos humanos. Una es la historización dialéctica. El ser humano es una realidad escindida entre el que disfruta del derecho y el que lo padece. "Más pertinente para nuestro problema, es una realidad dialéctica entre el fuerte y el débil, entre el señor y el esclavo, entre el opresor y el oprimido"36. De ahí que el método adecuado para buscar y encontrar un derecho eficaz y dinámico es "negar superadoramente aquella condición de debilidad, esclavitud y opresión"37. Y esa dialéctica hay que mantenerla también a la hora de hacerlos prevalecer. "El problema radical de los derechos humanos es el de la lucha de la vida en contra de la muerte, la busca de lo que da vida frente a lo que la quita o da muerte"38.

La segunda es historizar y jerarquizar los contenidos. Ellacuría insiste en abordarlos desde lo fundamental de la vida. Este derecho a la vida - sobre todo el de mayorías y pueblos - antes que cualquier otro derecho, exige historización $n^{39}$ de lo que se entiende por vida. La mera vida biológica "puede parecer algo sobreentendido en los países más ricos, que tienen asegurado este derecho..., pero no es así en la mayor parte de los países, sea por la extrema pobreza, sea por la represión y la violencia"40. De ahí que la proclamación de la esencia universal de los derechos humanos pueda ser falaz, irresponsable e ideologizada, pues "para la mayor parte de la humanidad... no se dan las condiciones reales para poder seguir viviendo biológicamente - hambre y falta de trabajo"4!.

34. "Historización de los derechos humanos desde los pueblos oprimidos y las mayorfas populares", ECA 502 (1990) 590. Puede verse lo que escribí en "Los derechos humanos y los pueblos oprimidos. Reflexiones histórico-teológicas", Revista Latinoamericana de Teologia 43 (1998) 79-102.

35. "Historización", p. $\mathbf{5 9 0 .}$

36. Ibid.

37. Ibrd., p. 591.

38. Ibrd., p. 593.

39. lbid. p. 590

40. Ibrd. p. 593.

41. $l$ bid. 
A estas sospechas, quisiera añadir, de forma breve, otras dos que, por lo que recuerdo, Ellacuría las expres 6 de manera más implícita. Una es sobre la libertad de expresión, que esencialmente es presentada como un derecho - cosa buena, sobre todo en nuestros países -, pero que no tiene por qué ir unida a la voluntad de verdad. Históricamente, no ocurre con frecuencia. Y no sólo eso, aquélla puede encubrir la ausencia de ésta, con lo cual "lo bueno" es puesto históricamente al servicio de "lo malo".

La otra es sobre la prosperidad, ansiada hoy en día con verdadera compulsión de vivir mejor, de bienestar "sin límites", sin pensar en que eso pueda ser también deshumanizante para quienes lo disfrutan y para los otros que tienen que pagar los costos. Esta neurosis se expresa, además, en innumerables signos de boato y faraonismo, sociales y, a veces, también religiosos, Singapur, mundiales, nupcias... Esta prosperidad y estos alardes no están guiados por la voluntad de humanización. Hacen que la mirada se desvíe de la realidad de las mayorías, que no son beneficiarios directos de la prosperidad y su apoteosis, y se dirija hacia las minorías, presentadas como bienhechoras económicas, que, además, posibilitan entretenimiento, felicidad en suma. Ante la apoteosis del progreso que nos ofrecen, bueno será recordar las reflexiones de J. Moltmann sobre el futuro del nuevo milenio: "progreso y precipicio" $\lrcorner 2$.

Ellacuría fue profeta y denunció males, pero también sospechó y enseñó a sospechar de lo que, siendo, o pudiendo ser bueno, se presenta como bueno sin discusión, siendo así que puede ser puesto al servicio del mal. Y pudo hacerlo porque "se hizo cargo" no de cualquier realidad, sino de la realidad permanente de pueblos crucificados - a pesar del progreso y de las democracias circundantes, y de la declaración universal de derechos humanos que teóricamente los defiende.

\subsection{Civilización de la pobreza}

La civilización de la riqueza no "civiliza". A ella opuso Ellacuría la civilización de la pobreza, a lo cual dedicó mucho pensamiento teórico en los últimos años de su vida, aun en medio de urgencias de todo tipo. Pensó que era el modo adecuado de historizar "la civilización del amor" de que hablan los papas. Y lo mantuvo hasta el final, bastante en solitario, con la excepción, que yo recuerde, de Pedro Casaldáliga: “A 'la civilización del amor' debería añadírsele aquello que con expresión feliz designó el teólogo jesuita, español, vasco, salvadoreño, Ellacuría, como 'la civilización de la pobreza"'43.

42. En Revisia Lafinoamericana de Teología 54 (2001) 235-253.

43. "A los quinientos años: 'descolonizar' y 'desevangelizar'", Revista Latinoamericana de Teologra 16 (1989) 118 . Después, Casaldáliga ha hablado de la civilización de "la pobreza solidaria". 
Empecemos con una aclaración. Ellacuría no pretendía, obviamente, la pauperización universal. Si hablo de la civilización de la pobreza fue para contraponerla a la civilización de la riqueza. En un mundo configurado pecaminosamente por el dinamismo capital-riqueza es necesario suscitar un dinamismo contrario que lo supere salvíficamente. De ahí la tesis: la civilización de la pobreza "rechaza la acumulación del capital como motor de la historia y la posesion-disfrute de la riqueza como principio de humanización, y hace de la satisfacción universal de las necesidades básicas el principio del desarrollo y del crecimiento de la solidaridad compartida el fundamento de la humanización" $"$.

La afirmación positiva programática, sin bajar a detalles, es la siguiente: la civilización de la pobreza es "un estado universal de cosas en que esté garantizada la satisfacción de las necesidades fundamentales, la libertad de las opciones personales y un ámbito de creatividad personal y comunitaria que permita la aparición de nuevas formas de vida y cultura, nuevas relaciones con la naturaleza, con los demás hombres, consigo mismo y con Dios"

Dice Ellacuría que esa civilización de la pobreza está "fundada en un humanismo materialista, transformado por la luz y la inspiración cristiana"46 y quisiera decir una palabra sobre esto último. Como telón de fondo de la civilización de la pobreza y su capacidad de humanizar está la tradición bíblico-jesuánica. Ya dijimos cómo, en Isaías, el pueblo crucificado puede traer salvación, pero, más en general, la tradición de todo el Antiguo y del Nuevo Testamento es experta en la salvación que proviene de los pobres y pequeños: una anciana estéril, el diminuto pueblo de Israel, un judío marginal...

Y en el caso de Ellacuría está también operante, debidamente historizada, material y socialmente, la tradición ignaciana de las dos banderas ${ }^{47}$. Se afima en esa meditación que hay dos caminos que deciden la vida, la salvación o la maldición: uno que comienza con la pobreza y lleva, por su naturaleza, a la humanización integral, y otro que comienza con la riqueza y lleva, por su naturaleza, a la deshumanización integral. La pobreza - de nuevo debidamente historizada- es "principio" de bienes, y además, puede liberar de los males de los cuales es principio la riqueza. Y no es casual que entre jesuitas, que además son del tercer mundo, se encuentra hoy también esta intuición. En Asia, A. Pieris; en Africa, E. Mveng; además del mismo Ellacuría, en América Latina, retoman la tesis: los pueblos e iglesias pobres salvarán a los pueblos e iglesias ricas. También J. Comblin ve en la pobreza un espíritu positivo, de alegría, que contrapone al espíritu de la riqueza. Dice: "He conocido barracas construidas sobre el mar

44 . "Utopía", p. 170.

45. "El reino de Dios", p. 595.

46. "Ulopla", p. 170.

47. "Lectura latinoamericana", pp. 128-133. 
en El Salvador donde viven miles de personas en condiciones muy precarias, incluso con peligro de caer al agua. Pero la gente vive allí con una alegría, con una conciencia, una apertura y una paciencia que son el reverso del mundo de los ricos"48.

Por esa civilización de la pobreza hay que trabajar para que llegue a ser realidad o para que sus elementos sean impulso importante hacia una nueva realidad. No basta con predicarla como profecía contra la civilización de la riqueza, ni siquiera sólo con anunciarla como buena noticia para los pobres de este mundo. La solución "no puede estar en un salirse de este mundo y hacer frente a él un signo de protesta profético, sino en introducirse en él para renovarlo y transformarlo hacia la utopía de la tierra nueva" 49 .

En ese contexto, Ellacuría propone dos formas fundamentales de emprender la transformación de la actual civilización. Una, la más comprensible y aceptada, al menos por algunos, es "crear modelos económicos, políticos y culturales, que hagan posible una civilización del trabajo como sustitutiva de una civilización del capital"so. La otra consiste en robustecer "positivamente una característica fundamental de la civilización de la pobreza, la solidaridad compartida, en contraposición con el individualismo cerrado y competitivo de la civilización de la riqueza"si. Y esa solidaridad no es sólo un elemento importante para pensar $a$ priori la nueva civilización que se pretende, sino que recoge a posteriori algo fundamental de la tradición cristiana y de las mejores tradiciones latinoamericanas, superadoras de tendencias individualistas disociadoras.

Mencionar la solidaridad es introducirse en un ámbito de la realidad que no es meramente el de lo eficaz instrumental. Es hablar de "espíritu", de lo eficaz espiritual. $\mathrm{Y}$ eso me parece ser lo más llamativo del pensamiento de Ellacuría, al analizar la realidad social global: su insistencia en el espíritu que informe una nueva civilización, y que puede ser generado muy principalmente por los pobres.

Esa pobreza es la que realmente da espacio al espíritu, que ya no se verá ahogado por el ansia de tener más que el otro, por el ansia concupiscente de tener toda suerte de superfluidades, cuando a la mayor parte de la humanidad le falta lo necesario. Podrá entonces florecer el espíritu, la inmensa riqueza espiritual y humana de los pobres y los pueblos del tercer mundo, hoy ahogada por la miseria y por la imposición de modelos culturales más desarrollados en algunos aspectos, pero no por eso más plenamente humanos ${ }^{52}$.

48. Entrevista en Éxodo $78-79$ (2005) 66.

49. "Utopia", p. 172.

50. "El desafío", p. 1078.

51. "Utopia", p. 172.

52. "Misión actual", p. 119s. 
Estas son palabras notables: la inmensa riqueza espiritual y humana de los pobres y de los pueblos del tercer mundo. Esto no significa cegarse a los males que genera la pobreza, ceguera a la cual no era nada dado Ellacuría. Tampoco es fácil poner en palabra qué sea ese espíritu, y en definitiva pienso que sólo puede hablar de él, indefensamente, quien lo ha experimentado. Dicho en las palabras más sencillas posibles, en contacto con el tercer mundo muchos encuentran "algo" que no cncuentran en el mundo de la riqueza, y ese "algo" es de una calidad humana superior al que éste produce.

Dice J. Comblin, "En los medios de comunicación se habla de los pobres siempre de forma negativa, como los que no tienen bienes, que no tienen cultura, que no tienen para comer. Visto desde fuera, el mundo de los pobres es todo negatividad. Sin embargo, visto desde dentro, el mundo de los pobres tiene vitalidad, luchan para sobrevivir, inventan trabajos informales y construyen una civilización distinta de solidaridad, de personas que se reconocen iguales, con formas de expresión propias, incluidos el arte y la poesía"s3. Monseñor atribuía al pueblo, las mayorías populares, una fuerza especial. "Empuja a su servicio", decía (Homilía del 18 de noviembre de 1979), y a Ellacuría le impactaba que Monseñor captara en el pueblo "una capacidad de encontrar salidas a las dificultades más graves"s. Viendo de lejos a los refugiados de Rwanda, y de cerca a muchas comunidades salvadoreñas, en tiempos de guerra, de terremoto y en la cotidianeidad de su vida, he hablado de "santidad primigenia", su decisión de vivir y de compartir vidass. La expresión "calidad de vida" no ha nacido en el mundo de los pobres, pues presupone la vida, mientras que los pobres no la dan por supuesto. Pero de ese mundo sf emergen "impulsos de vida", antes de que ésta quede cosificada y sea pensada, en buena medida, desde y para el consumismo de la civilización de la riqueza. De los pobres puede surgir humanidad, acogida, comunidad, arte, cultura, teología.

Ellacuría no era simplista, ni injusto. Conocía y apreciaba los avances en ciencia y tecnología, que pueden ser puestos al servicio de lo humano, y también modelos culturales y expresiones de espíritu en occidente. Hoy se valora la tolerancia y el diálogo - aunque, unilateralizados, no dejan de tener graves peligros-, también hay avances en solidaridad, aunque a veces de forma vaga y aun egocéntrica, entendida unilateralmente como ayuda al que sufre, más que como dar y recibir también del que sufre.

Pero esto no es suficiente. Se necesita un nuevo quicio sobre el que giren de forma humana los diversos elementos que configuran a una sociedad. La civilización de la pobreza, que proviene fundamentalmente del espíritu de los pobres -y del de Jesús -, genera valores que, unidos a lo más genuino de las tradicio-

53. Op.cit., p. 66.

54. "La UCA ante el doctorado concedido a Monseñor Romero", ECA (1985) 168.

55. Terremoto, terrorismo, barbarie y utopía. El Salvador, Nueva York, Afganistán, Madrid, 2002, pp. 125-135; San Salvador, 2003, pp. 129-140. 
nes civilizatorias del pasado y a las mejores en el presente, puede crear el nuevo quicio. Esto supone revertir el dogma de que el mundo girará bien, en definitiva, sólo alrededor de la riqueza.

Cuál sea ese quicio, lleno de un nuevo espíritu, no es fácil decirlo, pero quizás lo que vamos a decir pueden ser elementos de ese espíritu: (a) estar en la realidad, superando el docetismo de vivir en la irrealidad, en islas de abundancia, ajenos, desentendidos, de las mayorías de pobres, oprimidas; (b) la honradez con lo real, superando mentira y encubrimiento con la voluntad de verdad, poniendo nombre a los millones de víctimas y mártires, haciendo memoria de ellos, de cuya savia vivimos; (c) la compasión ante el sufrimiento de inmensas mayorías, denunciando proféticamente la injusticia que las produce; (d) la exigencia de una libertad de y para todos, y por lo que toca a la propia libertad, comprenderla, en definitiva, de modo que nada esclavize, que nada sea obstáculo, para hacer el bien; (e) cargar con el peso de la historia, cotidianamente y hasta el final; (f) el gozo de sabernos todos hermanos y hermanas, que puede ir acompañado del sufrimiento, pero que no puede ser arrebatado por la tristeza, y la celebración de ese gozo; (g) el cuidado de la naturaleza y de toda la creación, dentro de la cual formamos una unidad mayor; (i) la esperanza utópica de un nuevo cielo y una nueva tierra; (j) la apertura a un misterio último de la realidad $-y$, para algunos, el salirse de uno mismo, como en la oración de san Francisco de Asís, y el poner nombre a eso último, Padre, Madre, sin quitarle lo que tiene de inefable y misterioso, Dios.

Al terminar el primer punto dijimos que causa estupor lo que dice Ellacuría sobre el pueblo crucificado. Lo mismo, si no más, ocurre con lo que dice sobre la civilización de la pobreza. Terminemos con unas brevísimas reflexiones, no para eliminar el estupor, pero sí, quizás, para ubicarlo bien.

En primer lugar, Ellacuría conocía los grandes males que se dan en el mundo de la pobreza, y los males que cometen los pobres, por su condición humana, por la inclinación a ello que producen las carencias, por introyectar lo deshumanizante de la civilización de la riqueza, lo hagan forzados y engañados o de buen grado. No era ingenuo. Pero no vio otro modo para superar la mayor deshumanización de la civilizacion de la riqueza que el espíritu que surge en la civilización de la pobreza. Y en positivo, lo cautivaba su creatividad, su generosidad, su firmeza, su solidaridad, su austeridad, su esperanza, su apertura a la transcendencia.

En segundo lugar, Ellacuría sabía que sin poder no se mueve la historia, En su tiempo, en medio de la lucha popular por construir una nueva sociedad, reconocía la necesidad y la legitimidad del frente-político, que buscba el poder, pero daba prioridad a la organización-base, que no buscaba llegar al poder. "Lo social es más básico que lo político", decía ${ }^{56}$. Pienso que en eso insistiría para

56. Sobre ello escribió un importante artículo, "El papel de las organizaciones populares en la actual situación del país", ECA 372-373 (1979). 
construir la civilizacion de la pobreza. En ese sentido, Ellacuría tampoco cayó en el "mesianismo", como a veces se ha acusado a los teólogos de la liberación, aunque valoraba la mesianidad, que caracteriza a la fe bíblico-jesuánica, es decir, mantener la esperanza de los pobres, pero con el paciente trabajo. Quizás influyó en ello el que en El Salvador no triunfó la revolución, como en Nicaragua, sino que la construcción de la nueva sociedad siempre iba en contra de los poderes establecidos. Y el que sus té́logos, sacerdotes y agentes de pastoral nunca estuvieron en el poder, ni fueron favorecidos por el poder, a diferencia de lo que ocurrió, en mayor o menor medida, en Brasil y Nicaragua.

Por último, preguntémonos de dónde le vino mantener la utopía y formularla como "civilización de la pobreza". Hay que recordar que Ellacuría estuvo siempre obsesionado por la justeza, es decir, por ajustarse a la realidad y a sus reales posibilidades. Fue además realista para dar los pasos posibles para que la realidad siempre diese más de sí. Pero eso no lo convirtió en oportunista, ni en mero posibilista. También estaba convencido de que para hacer avanzar la historia se necesitaba profetismo y utopía. Y con eso volvemos a hacer la pregunta por el origen de esa utopía. Esta tenía, sin duda, raíces personales, pero queremos recalcar un elemento objetivo e histórico al cual él mismo apuntó: "hay unos lugares más propicios al surgimiento de utopistas proféticos y de profetas utópicos"s7. En concreto, el lugar que hace posible pensar pensar la "civilización de la pobreza", no es el mundo de la abundancia, de exaltación del individuo, del éxito y del buen vivir. Menos aún es el mundo de la prepotencia: "lo real somos nosotros". El lugar en que convergen como por necesidad profetismo y utopía es el tercer mundo, donde la injusticia y la muerte son intolerables, y donde la esperanza es como la quintaesencia de la vida. En ese mundo se encarnó conscientemente Ellacuría.

No sé que diría hoy Ellacuría, en tiempos de globalización y postmodernidad. Por mi parte, quisiera terminar expresando una convicción y un deseo. La convicción es que "a Ellacuría lo mataron por enfrentarse a la civilización de la riqueza". Y el deseo es que "no le dejemos morir por defender la civilización de la pobreza".

57. “Utopía", p. 141. 